\title{
Merit and Evaluation Models for Managers in the National Health System: An Empirical Study*
}

\author{
Elena Candelo, Cecilia Casalegno \\ University of Turin, Turin, Italy
}

\begin{abstract}
The national health system (NHS) complexity increase requires a review of the managerial human resources evaluation and recruiting methods, considering that nowadays doctors need to improve not just their clinical capabilities, but also managerial competences. At this end it is important to develop performances control models and to identify appropriate results indicators, with the aim of introducing an effective doctors selection system for managerial roles. The paper considers the Italian situation and tests the current evaluation and selection methods, by analysing the literature and the existing legislation and by interviewing experts. Moreover, in order to reach an innovative model, complex organizations have been taken into account as benchmarks. Three different categories of experts have been interviewed and texted: national health care organizations managers, companies managers, and business consultants. The 137 interviewed experts have been asked about four main questions concerning the evaluation for hiring managers as chief medical director, department director, and head of complex units. The conducted research suggests four different options in order to evaluate and to select heads of complex unit for the most strategic roles. By consequence, the analysis shows that required characteristics must be managerial attitudes as well as clinical capabilities.
\end{abstract}

Keywords: evaluation methods, national health care system, clinical governance, skills development, competences-based management, managerial competencies

\section{Introduction}

\section{Management, Leadership and Development Evaluation in the Italian National Health System}

The more your human resources are skilled, trained, and involved, the better your organization will profit. This is one of the human resource management bases. As Ulrich and Lake (1990) pointed out "the human resource management (HRM) system can be the source of organizational capabilities that allow companies to learn and to capitalize on new opportunities". After this premise, is possible to look at human capital as a distinctive asset in order to grow and evolve, every time more (Bahra, 2001; Griliches, 1996; Pfeffer, 1999;

\footnotetext{
* Acknowledgments: The Authors own full responsibility of the contents of the paper. Although this paper is based on collaboration, Prof. Elena Candelo Ph.D., is to take credit for paragraphs named "Management, Leadership and Development Evaluation in the Italian National Health System”, "Italian Current Evaluation Methods” and Dr. Cecilia Casalegno, Ph.D., is to take credit for paragraphs "Evaluation as the Key Factor for a Proper Management: The Competencies-Based Management”, "Research Design”. Anyway, both Prof. Candelo and Dr. Casalegno are to take credit for paragraph named "Key Findings" and "Literature and Suggested Steps".

Elena Candelo, Associate Professor, Department of Management, University of Turin.

Cecilia Casalegno, Researcher and Lecturer, Department of Management, University of Turin.

Correspondence concerning this article should be addressed to Elena Candelo, Corso Unione Sovietica 128 bis, Torino, Italy. E-mail: elena.candelo@unito.it.
} 
Caudron, 2004; Armstrong, 2006; Kaplan \& Norton, 2004). This means not only to motivate people, but also to assure that they can develop and grow. This is applicable to "for profit” realities, but even for "no profit" ones; the strategic assets management, in this case, not only ensures more effectiveness, but also more efficiency. Whatever is the strategy adopted by the company, no matter how conceived, it is doomed to fail until it is not implemented efficiently (Casalegno, Pellicelli, \& Civera, 2012). Especially talking about the national health system (NHS) in Italy, it is possible to highlight how central is the role of management; this role is as crucial as difficult because to those who have management and coordination responsibility is required-at different levels — not just to have the best skills required for their profession (in this case doctors with a lot of experience, an extensive clinical cases, and a certification of their scientific activity) and to be able to share and apply the guidance of a multi-year plan, but also to lead, motivate, and enhance their employees, so that the whole structure points to improve continuously, to be able to assess with accuracy others work, to influence in a positive way organizational behaviors; to possess, in short, the characteristics set that distinguishes a good leader (Various Authors, 2006). Starting from the analysis of their ability to manage - that is not normally learned through academic courses - it should be noted that an effective management, organizing people working groups, must drive them towards a common mission and lead them by giving example and motivating. If what has just been said is not simple in "for profit" sector, the problem is even bigger in public sectors, where it is more difficult to share common goals, have a clear perception of the "added value" concept and, above all, consider the competitive advantage concept.

Talking about the Italian National Health System (INHS), it is necessary to consider that, established in 1978, it follows the British model (the Beveridge model, developed in 1942) ${ }^{1}$ and it is fed by citizens' taxes. This kind of coverage "provides uniform healthcare access to citizens" (Nuti, Seghieri, \& Vaineri, 2012). Moreover, it must be underlined that, from the beginning of the 1990s, Italian system has developed a strong policy of decentralization, facing a power shifting from the central government to the 21 Italian regions, which have, nowadays, a strong autonomy in managing the local public health system and in allocating the financial resources (Nuti et al., 2012). The decentralization has taken to a devolution of power: On the one hand, it is necessary to consider a central government, planning and managing guidelines and main resources, on the other hand, the 21 regional governments allocate financial resources to the local units named "Azienda Sanitaria Locale” (Local Health Structure) or "ASL" which is divided in several departments (one or more for every medical field). Each department is composed by various complex units skilled in different medical specialties. Departments are public organizations legally creatures of the region (Francea, Taronib, \& Donatini, 2005) and every region is governed by a president. Talking about the managerial roles of an ASL, the following must be considered:

- General director (GD) of the ASL—named by the regional president "without any kind of comparative evaluations" (art.3, comma 6d., Lgs: 502/1992);

- Accounting director - named by the GD with reasoned disposal;

- Chief medical director-named by the GD with reasoned disposal. He/she manages sanitary services and GD support activities;

- Department director — named by GD;

- Head of complex unit—named by the GD, he/she manages the complex unit;

${ }^{1}$ To go deeper, see Nuti et al. (2012) and Francea et al. (2005). 
- Complex unit assistant—named by the GD according to the suggestion of the head of complex unit.

The concept of leadership would therefore take to recognition of a continuing education which should not fear structural and organizational barriers. The research conducted in 2010 by Walson, Chou, and Khaliq shows that also on the other side of the ocean the propensity to a continuing education-and its managerial involvement of health professional figures - is greater in the private practice, which is definitely more focused on short-term horizons and some motivations efficiency-related may characterize the willingness to supply training. On the opposite side, in NHS structures, slower in strategic decisions and characterized by a more fragmented reality, most of the energies of health care managers are required for conducting their own professional activities with the responsibilities involvement related to it. Who really is the chief? A doctor? A manager? Both? If the latter is the answer, when and how can he/she really achieve and consolidate his/her management capabilities that until now have not been part of his/her education and career? Even if the answers are difficult to find, it is clear that doctors should be trained on the job and in a continuous manner. One of the research conclusions carried out in 2010, concerns, in fact, the inverse proportionality now exists between the organizational structure and the lifelong learning concept, proportionality that could be reversed if the continuous improvement would be included in the aims of the same organization (Pfeffer \& Salancik, 1978; Kimberly, 1976).

\section{Evaluation as the Key Factor for a Proper Management: The Competencies-Based Management}

Training and learning are key levers to bring competitive advantage to an organization which, such as a health care one, must manage continuous change. Literature supports the point of view which sees the propensity to change of a sanitary company for becoming a true learning organization (Tichy, 2004) is closely related to the amount of time that managers invest in their capabilities and skills development (Lee \& Herring, 2009).

A health quality service requires to focus on the management of each individual staff, with their own skills. This is why an innovative management takes charge of every professional and brings him/her closer to the skills system required to his/her role, through a series of custom development. This is accomplished by identifying personal skills gaps and associating them to some development activities built on the specific needs of each. Competencies-based management is the process through which activities are concentrated on staff management and are not only limited to focusing on general population employed examination, but also their verify skills—such as knowledge, skills gained in relation to their personal faculties—requested to the employees to get the whole organizational structure able to achieve their goals (Bonder, Bouchard, \& Bellemare, 2011). This methodology is improving, for the public administration, its importance since there is a greater awareness of the impact on business performance of internal know-how. The study and the identification of skills, related to outstanding performance, can establish, in an innovative way, the managerial policies of the entire human resources turnover. The challenge is double: On the one hand it is necessary to train human resource in its own individuality and on the other hand it is necessary to include the worker in a collective context.

The competencies-based management involves an assessment of the skills in order to enable the achievement of defined objectives, for example, leading to the identification of the best candidate in a selection process. This is not a total new field of research; a research carried out in 1993 showed how effective can be the most used and well-known assessment methods as shown in Table 1 (L. M. Spencer \& S. M. Spencer, 1993). 
L. M. Spencer and S. M. Spencer (1993) depicted some of these skills called "generic" (see Table 2), adaptable to every managerial level; this scheme is suitable to be adapted for a complete senior figures assessment in public health who, as it has already been said, not only have to prove their managers capabilities but, in the present state of things, have also to pursue their clinical and scientific activity.

Table 1

Correspondence Between Selected Profile and Performance Provided in the Working Position

\begin{tabular}{ll}
\hline Evaluation method & Correspondence (MAX = 1) \\
\hline Assessment center & 0.65 \\
Bei & $0.48-0.61$ \\
Practical tests & 0.54 \\
Ability tests & 0.53 \\
Personality questionnaires & 0.39 \\
Bibliographic & 0.38 \\
References & 0.23 \\
Interviews (not Bei) & $0.05-0.19$ \\
\hline
\end{tabular}

Note. Source: L. M. Spencer and S. M. Spencer (1993).

Table 2 demonstrates, in a generic manner, the complexity of managerial figure in public domain or, rather, public health; we are faced with a high degree of skills overlapping, not simple—-therefore—-to assess.

Table 2

"Generic" Managerial and Clinical Skills

\begin{tabular}{|l|l|}
\hline & Persuasiveness \\
& Stress to the result \\
& Teamwork \\
& Analytical thinking \\
& Initiative \\
& Development of other \\
& Self-confidence \\
& Leadership ability \\
& Continuous research of information \\
& Strategic leadership \\
\hline \multirow{2}{*}{ Clinical/scientific skills } & Conceptual thinking \\
\hline & Continuous updating \\
\hline Basic requirements & Continuity in publications \\
& Working groups coordination \\
\hline
\end{tabular}

Note. Source: L. M. Spencer and S. M. Spencer (1993).

The competencies-based management leads to identify which skills—and in which way-have to be used, according to each different role in an organization chart of a certain reality. The selection, therefore, has to be focused on identification and definition of skills a certain role needs to possess. In public sector is not so easy to identify the recruiting model leading to efficiency and effectiveness results; it is necessary therefore to have a methodology that considers the context in which the new resource will have to express his/her potential and to place the newcomer in a position useful to give his/her best. In order to show the complexity and the necessity of a new perspective of the current evaluation method, this research has texted interviewed concerning the role 
of head of complex unit; once that it has been selected the person, he/she is placed in a completely new context. Until that time his/her activity was clinical and scientific, but now it is necessary that the responsibility moves his/her attention to a third activity, to which probably is not very prepared; it is the managerial one (or even more simply administrative), which, of course, implies use of different capacities from those learned during his/her university studies and specialty.

\section{Italian Current Evaluation Methods}

Since what said above is fundamental to understand how in companies roles are managed in order to understand in which way people and managers can be hired, evaluated, and monitored in the NHS.

The objective is to define meritocratic models of development and transparency in sanitary service with the purpose of elaborating methods to recruit top human resources in a sanitary system using efficiency and effectiveness criteria.

The following is the result of a research based on different methods: analysis of currently used methods, experienced interviews, benchmarking of complex organizations, and literature analysis of the subject (top human resources management).

Questions to answer are the following:

(1) Considering the experience of private companies and complex organizations management, is it possible to get suggestions and indications to give greater transparency, effectiveness, and efficiency in the selection and the heads of complex unit designation?

(2) How is it possible to integrate the existing rules for the appointment of the head of complex units with other methods?

(3) Which skills, attitudes, behaviors should be requested to candidates for the analyzed roles in order to maximize the efficiency and effectiveness of the organization?

The final aim is to deliver methods, models, and tools to general directors, supporting them and helping in the selection of various managerial roles.

Current assessment methods. First of all, the research has analyzed the selection procedures concerning the most important roles in the public healthcare system. The process develops as follows.

GD names the department director choosing him/her among three eligible candidates. A committee composed by three members assigns the eligibility using a competition. The committee is composed by the chief medical director and by two other members (heads of complex unit) of whom one is selected by GD and the other one comes from the ASL board. They are selected between two groups of heads of complex unit (three from the region considered and three from other regions) drawn from a complete list prepared by the region (this list is taken from complete lists created by chief medical director of different ASLs in the national territory, divided in various disciplines). The GD chooses his/her commission member among the three extra regional candidates, while the ASL makes its choice take into account the other group.

\section{Research Design}

In order to shape key findings, four methods are being used:

(1) Study of legislation. An Analysis of existing legislation at national and regional level has been conducted;

(2) Interviews. Experts of three different categories have been interviewed: 
- Managers of healthcare organizations: GD, accounting directors, chief medical directors, department directors, Heads of complex unit, complex unit Assistants, Doctors, Agenas (which is the acronym for the Italian translation of "National Agency for Regional Health Care Services”) Director, Italian Regions managers;

- Companies managers with responsibility in complex organizations;

- Consulting firm managers specialized in recruiting and in strategic human resource management.

(3) Literature analysis of the subject. There is a vast literature on how to select managers of complex organizations;

(4) Benchmarking of complex and for profit organizations.

\section{Key Findings}

Thanks to the competencies-based management which is possible to define skills and knowledge have to be implemented for the analyzed assessment methods. Moreover the performances evaluation can be developed by using a decision tree, as shown in Figure 1. The expected results may be the following: reduction in resources turnover, equal opportunities, entrance training, and faster learning curves. The development the competency-based management requires to implement three different phases such as: development of competency tasks models (it is a preliminary phase in which is defined a schedule of tasks and features necessary to carry them out effectively); choice of assessment tools for defining the most appropriate definition skills for evaluation method of job-person matching (parameters of effectiveness and efficiency); objective parameters-related to the role for which you are doing selection and, above all, assessed in an absolute sense, can objectively help to decide the proper person for a certain role, beyond the nature of evaluators themselves (internal or external).

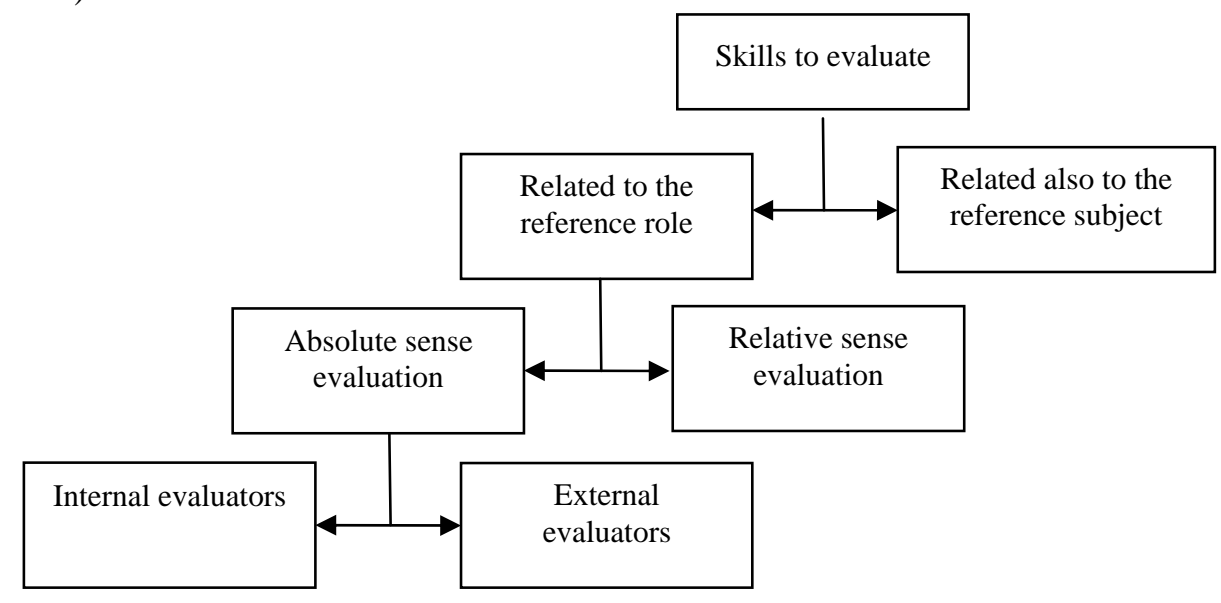

Figure 1. Decision tree related to skills selection. Source: Various Authors, 2006.

Table 3 shows about achieved results from personal interviews; how is possible to see, not just health care managers are considered, but also strategic roles coming from private sectors. Interviewed have been asked about four main questions concerning the evaluation for hiring managers as chief medical director, department director, and head of complex units: (Q1) the necessity of testing managerial skills and attitudes; (Q2) the peer evaluation; (Q3) the importance of an evaluation thought the resumes analysis; and (Q4) the necessity of a practical test (case methods), in order to test the medical knowledge of a doctor. 
Table 3

Interviewed Managers and Consultants (Correspondence: $M A X=1$ )

\begin{tabular}{lcllll}
\hline Role & Quantity & Q1 & Q2 & Q3 & Q4 \\
\hline Chief medical directors & 3 & 0.65 & 1 & 1 & 0.75 \\
Department directors & 10 & 1 & 0.85 & 1 & 0.50 \\
Heads of complex unit & 30 & 0.50 & 1 & 1 & 0.75 \\
Doctors & 50 & 0.40 & 0.50 & 1 & 0.50 \\
Firms' CEO & 3 & 1 & 1 & 1 & 1 \\
Consultants and experts in & 20 & 1 & 0.75 & 1 & 1 \\
human resources management & & & 1 & 1 & 1 \\
For profit companies managers & 20 & 1 & 1 & 1 & 0 \\
Agenas director & 1 & 1 & & & \\
\hline
\end{tabular}

Note. Source: Authors’ processing.

Going deeper, characteristics considered in evaluating a candidate-for the position of head of complex unit—concern both clinical and managerial skills and attitudes summarized in Table 4.

Table 4

Major Assessment Characteristics Required

\begin{tabular}{|c|c|c|}
\hline IVId & VIdIIdgendal dtutuue & Clinical capacity \\
\hline $\begin{array}{l}\text { - To introduce, in compliance with existing legislation, } \\
\text { mechanisms that increase the efficiency and effectiveness } \\
\text { of the organization } \\
\text { - To share and to assign different goals to employees and } \\
\text { measure the results achieved } \\
\text { - To evaluate employees focusing on the achievement of } \\
\text { their goals } \\
\text { - To reward deserving employees (examples: with bonus, } \\
\text { with participation in conferences, with the involvement in } \\
\text { - decisions, with direction of simple structures) } \\
\text { - To delegate decisions and activities } \\
\text { - To motivate employees } \\
\text { - To apply the principles of Total Quality Management } \\
\text { - To find to health care organizations } \\
\text { references } \\
\text { - To start from the benchmark positions and adjust } \\
\text { - To create a climate conducive to productivity } \\
\text { - To identify the right workloads in relation to resources } \\
\text { - Tavailable } \\
\text { - Peam work } \\
\text { - Toblem-solving: analyze problems, identify possible } \\
\text { solutions and simplify } \\
\text { - Continuous improvement } \\
\text { - To apply the techniques of budgeting } \\
\text { - To attract funding } \\
\text { - To negotiate with parties (examples: employees of } \\
\text { - Tepartment or division) } \\
\text { - So intervene in emergencies } \\
\text { - Experience gained in management in Italy and abroad } \\
\text { - To manage complex systems } \\
\text { - To plan actions to achieve objectives }\end{array}$ & $\begin{array}{l}\text { - To act quickly and } \\
\text { decisively } \\
\text { - To place the customer } \\
\text { satisfaction among the } \\
\text { primary objectives } \\
\text { - To lead } \\
\text { - Teaching } \\
\text { - To act in accordance } \\
\text { with organization } \\
\text { ethical principles } \\
\text { - To treat people with } \\
\text { dignity and fairness } \\
\text { - To share information } \\
\text { - To manage interest in } \\
\text { contradiction } \\
\text { - To promote continuous } \\
\text { improvement } \\
\text { - To assess acceptability } \\
\text { or unwillingness to } \\
\text { compromise } \\
\text { - To discuss, debate, } \\
\text { negotiate } \\
\text { - To conceptualize, } \\
\text { improve, modify, check } \\
\text { - To communicate } \\
\text { To build relationships }\end{array}$ & 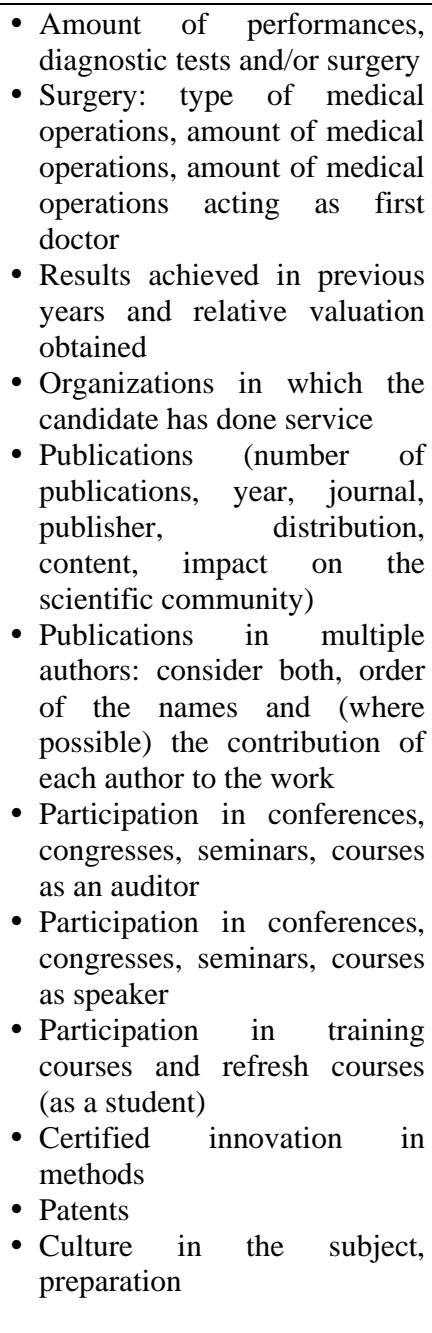 \\
\hline
\end{tabular}

Note. Source: Authors' processing. 
The competencies-based assessment when it is used in hospitals/healthcare system, is part of a wider scope; its applicability has been analyzed and changed from what has been done at the end of 1990s in UK in order to respond to the healthcare quality crisis, typical of those years (Bevan, 2008) in which were followed scandals in hospitals, together with the inability to give adequate responses. Walshe and Shortell (2004) thought that these scandals and response delays were linked rather to the internal nature of clinical practice, medical profession and, finally, to healthcare organization culture. In those years it was launched a program of "Clinical Governance Reviews". According to the British Department of Health (1998) the "clinical governance" is "a process to reduce deviations from standards of quality", "a responsible structure", and "applicable to all employees of the hospital”.

This approach was based on each hospital visit. Furthermore, the assessment was done by using multidisciplinary groups led by a manager (not necessarily clinical) and other clinical and not clinical staff. Table 5 shows the last two key factors elements.

Table 5

The Clinical Governance Elements in a Hospital

\begin{tabular}{|l|l|}
\hline $\begin{array}{l}\text { Resources and process: } \\
\text { - Quality process }\end{array}$ & Components element \\
& $\begin{array}{l}\text { Involvement of patient and general public } \\
\text { Clinical audit } \\
\text { Risk management } \\
\text { Programs of clinical efficacy }\end{array}$ \\
- Focus on staff & $\begin{array}{l}\text { Staff management } \\
\text { Continuous training of personal and professional } \\
\text { development }\end{array}$ \\
\hline Using of continuous information & $\begin{array}{l}\text { Using information to support clinical governance and to } \\
\text { delivery health services }\end{array}$ \\
\hline
\end{tabular}

Note. Source: Adapted from Bevan (2008).

The research has taken into account these conclusions and results come from interviews and literature review. The following steps or options are suggested in order to evaluate and to select heads of complex unit for the most strategic roles considered above. Evaluators can combine different presented methods, depending on clinical fields and ASLs organization.

In the following, the term "support committee" indicates the working group providing grants to the GD.

(1) The first option: "Peer evaluation". The option consists in submitting the candidates evaluation to their peers role colleagues, with the same or different clinical specialization. The support committee is composed by three members and the process is divided into three phases.

- Phase a: Constitution of the support committee. It can be through election or drawing;

- Phase b: Formalization of the support committee. Once elected, the committee is appointed by a higher authority that certifies and formalizes its existence and its role. Through this step, the committee members are easy known by any candidate in the competition. The committee formalization is a necessary requirement to make this method acceptable and its result sustainable;

- Phase c: Candidates evaluation. The support committee expresses its own judgments about capabilities, professional skills, and competences of candidates.

Two systems are suggested: The first one is about the resume evaluations, with a blind review if possible. The second one also considers a personal interview to check resume contents. 
The "peer evaluation" takes the following advantages. It considers advice from people who know the healthcare structure, as well as its complexity and it allows assessing the impact of the subject on the organization results.

(2) The second option: "Assessment by doctors who work in the structure the future head of complex unit will work in”. Since doctors currently working in the healthcare structure know problems and requirements of their workplace, a negative opinion may take to a loss in motivation and maybe the abandonment of the structure itself. Moreover, the better is the choice concerning the head of complex unit, the higher will be the healthcare structure prestige. Alternatively, in this case, the support committee may be constituted by:

- All the doctors in the same clinical field in the structure the future head of complex unit will work in;

- Bullet "a" doctors and doctors coming from other clinical field;

- Bullet "a” doctors and every ASL head of complex unit.

(3) The third option: "Assessment by expert people do not work in the structure the future head of complex unit will work in". In this case, the support committee is composed by: recruiting consultants specialized in management selection (i.e., Mercer, Hey), firm managers (human resource directors, top managers), former general managers of healthcare structures, doctors with experience in business management.

(4) The fourth option: Assessment by "case method". It is based on the belief that putting a group of people to solve a problem and inviting them to discuss with each other, it is possible-by one or more silent observers - to identify different elements: problem analysis, negotiation skills of the possible solutions, rationality of solutions, ability to work in teams, and ability to "fairness" (respect for different opinions). The support committee identifies a significant problem and asks candidates to solve it.

The option aims to recreate the conditions in which the future health physician will operate in reality. From the contribution and the behavior of each candidate in the group discussion, the observer is able to get useful indications. In this case the support committee is made by experts in case methods.

\section{Conclusions and Suggested Steps}

The conducted analysis has underlined the necessity-according to the collected answers—of the improvement of clinical governance, in order to build best professional skills in a system undermined by the central role of politics, together with the importance of private practice (Tousijn \& Giorgino, 2009). Clinical governance also means a program of continuous improvement in provided quality, based on the principle that leaders in the healthcare system should be responsible for their actions. Finally, this program also makes reference to a new model in which clinical judgment is combined with national standards, in contrast with centralized control—previously used-of clinical judgment and patients' needs. This has been taken up and developed in Italy since 2004 with the approval by the Ministers Council of the bill by Minister for Health Sirchia (Fontana, 2005). Methods and quality checks become, in this way, integral parts of a program under direct responsibility of the department board, which has, therefore, to prepare a multi-annual action plan. The main elements of clinical governance, as already implemented but to improve in Italy, are the following:

- Broadcast of guidelines. It refers to the adoption of a clear parameters instruction to be used for accounting within the public institution;

- Adoption of a clinical audit. This is the clinical performance check. It is the accurate check that must been done according to ISO parameters (quality management system), and controlling if achieved results meet main objectives; 
- Introduction of the risk management concept. Since it is possible to talk about patient's risk, health personnel's risk in general, and the risk on property itself, healthcare structures need to consider and use ongoing procedures review, by adopting quality standards (ISO) and planned procedures, and the management of adverse events (Giangrande, 2004);

- Transparency. Towards the patient and the community;

- Training and assessment. The training is on the job and the assessment must be continuous, considering that the role of chief must be taken by the best doctors with managerial skills;

- Research, development and the job evaluation. Considering that it comes from evaluating a structure in which the development is an essential element of the social object, this parameter is critical; the evaluation must be done not just at the beginning, in order to find the right person for a certain managerial role, but as a continuous process.

\section{References}

Armstrong, M. (2006). Strategic human resource management. Philadelphia: Kogan Page.

Bahra, N. (2001). Competitive knowledge management. N.Y.: Palgrave.

Bevan, G. (2008). Changing paradigms of governance and regulation of quality of healthcare. England, Health, Risk \& Society, 10(1), 85-101.

Bonder, A., Bouchard, C. D., \& Bellemare, G. (2011). Competency-based management-An integrated approach to human resource management. Public Personnel Management, 40(1), 1-9.

Casalegno, C., Pellicelli, M., \& Civera, C. (2012). Social values and ethics for communicating the corporate identity. Chinese Business Review, 11(7), 656-671.

Caudron, S. (2004). Metrics maverick. Workforce Management, 83(4), 49-51.

Department of Health. (1998). A first class service: Quality in the new NHS. London: Department of Health.

Fitz-Enz, J. (2001). Measure human resource management. N.Y.: McGraw-Hill.

Fletcher, R. H., \& Fletcher, S. W. (1979). Clinical research in general medical journals. N Engl J Med, 301, 180-3.

Fontana, F. (2005). Clinical governance: Unaprospettivaorganizzativa e gestionale. Milano: Franco Angeli.

Francea, G., Taronib, F., \& Donatini, A. (2005). The Italian health-care system. Health Econonimics, 14, 187-202.

Gatewood, R., Field, H. S., \& Barrick, M. (2007). Human resource selection. South-Western: College Pub..

Giangrande, A. (2004). Clinical governance, an introduction (Clinical governance, un'introduzione). Proceedings of the 45th National Congress of Società Italiana di Nefrologia.

Griliches, Z. (1996). Education, human capital, and growth: A personal perspective (No. w5426). National Bureau of Economic Research.

Kaplan, R., \& Norton, D. P. (2004). Measuring the strategic readiness of intangible assets. Harvard Business Review, 82(2), 52-63.

Kimberly, J. R. (1976). Organizational size and the structuralist perspective: A review, critique, and proposal. Administrative Science Quarterly, 21, 571-597.

Lee, B., \& Herring, J. (2009). Crowing leaders in healthcare: Lessons from the corporate world. Chicago: Health Administration Press.

McGinnis, J. M. (2009). Evidence-based medicine. Information Knowledge Systems Management, 8, 145-157.

Nuti, S., Seghieri, C., \& Vaineri, M. (2012). Assessment and improvement of the Italian healthcare system: First evidence from a pilot national performance evaluation system. Journal of Healthcare Management, 57(3), 182-198.

Pfeffer, J. (1999). Competitive advantage through people. Boston: HBS Press.

Pfeffer, J., \& Salancik, G. (1978). The external control of organizations. N.Y.: Harper Collins.

Pynes, J. E. (2008). Human resources management for public and nonprofit organizations: A strategic approach. Danvers, M.A.: John Wiley \& Sons, Inc..

Spencer, L. M., \& Spencer, S. M. (1993). Competencies in working systems: Models for a superior performance (Competenzanellavoro: Modelli per una performance superiore). Milano: Franco Angeli.

Tichy, N. (2004). The cycle of leadership. N.Y.: HarperBusiness. 
Tousijn, W., \& Giorgino, V. M. B. (2009). The complexities of negotiating governance change: Introducing managerialism in Italy. Health Economics, Policy and Law, 4(3), 329-346.

Ulrich, D., \& Lake, D. (1990). Organizational capability. N.Y.: JohnWiley.

Ulrich, D., Zenger, J., \& Smallwood, N. (1999). Result based leadership. Boston: Harvard Business School Press.

Various Authors. (2006). The competencies based management in public administration (La gestione per competenzenelleamministrazionipubbliche). Catanzaro: Rubettino.

Walshe, K., \& Shortell, S. M. (2004). When things go wrong: How health care organizations deal with major failures. Health Affairs, 23(3), 103-111.

Walson, S., Chou, A. F., \& Khaliq, A. A. (2010). Factors affecting the continuing education of hospital CEOs and their senior managers. Journal of Healthcare Management, 55(6), 413-427.

Wood, R., \& Payne, T. (1998). Competency-based recruitment and selection. Chichester: Wiley. 